\title{
As representações do cuidado voltado à pessoa que vive com HIV/AIDS para a equipe de saúde*
}

\author{
The care representations directed to the person who lives with \\ HIVIAIDS for the health team*
}

\author{
Priscila Cristina da Silva Thiengo ${ }^{1}$ Antonio Marcos Tosoli Gomes ${ }^{2}$ - Denize Cristina de Oliveira ${ }^{3}$
}

\begin{abstract}
RESUMO
Esta pesquisa objetivou analisar o cuidado em saúde ao paciente soropositivo através da abordagem processual a partir das representações construídas pela equipe de saúde. Trata-se de pesquisa qualitativa e descritiva, realizada com 23 profissionais de saúde de dois hospitais federais de referência em HIV/AIDS. Adotou-se o referencial da abordagem processual da Teoria das Representações Sociais. As entrevistas foram transcritas e submetidas à análise de conteúdo temática instrumentalizada pelo software Alceste. As principais formas de enfrentamento que estão pautadas no cuidado são representadas pelo apoio familiar e do profissional de saúde diante do diagnóstico positivo, do preconceito, da discriminação e até da falta de informação. Sua contribuição é imprescindível para a conscientização e participação ativa no processo de saúde/doença, bem como na percepção da continuidade e valorização da vida.
\end{abstract}

Palavras-chave: Síndrome de Imunodeficiência Adquirida; HIV; Assistência à Saúde.

\begin{abstract}
This study aimed to analyze the health care to the HIV patient through the process approach from the representations constructed by the health team. It is a qualitative and descriptive research, carried out with 23 health team from two reference federal hospitals to HIV/AIDS. Adopted the framework of the procedural approach of the Social Representations Theory. The interviews were transcribed and submitted to thematic content analysis instrumentalized by Alceste software. The main forms of coping that are grounded in care are represented by family support and health care professional before the positive diagnosis, prejudice, discrimination and even the lack of information. Your contribution is essential for the awareness and active participation in the health/disease process, as well as the perception of continuity and enhancement of life.
\end{abstract}

Keywords: Acquired Immunodeficiency Syndrome; HIV; Health Care Assistance.

${ }^{1}$ Mestre em Enfermagem. Professora Assistente do Departamento de Enfermagem Médico-cirúrgico da UERJ. Rio de Janeiro, Brasil. E-mail: profprithiengo@gmail.com. ${ }^{2}$ Doutor em Enfermagem. Professor Titular da Faculdade de Enfermagem da UERJ. Rio de Janeiro, Brasil. E-mail: mtosoli@gmail.com

${ }^{3}$ Doutora em Enfermagem. Professora Titular da Faculdade de Enfermagem da UERJ. Rio de Janeiro, Brasil. E-mail: dcouerj@gmail.com

*Este trabalho é parte da dissertação "A representação social do cuidado ao paciente soropositivo ao HIV/AIDS entre profissionais de saúde", apresentada ao Programa de Pós-Graduação em Enfermagem da Faculdade de Enfermagem da Universidade do Estado do Rio de Janeiro (UERJ), 2013.

Os autores declaram não haver conflito de interesse nem fontes de financiamento. 


\section{INTRODUÇÃO}

Deste a sua descoberta até os dias atuais, a Acquired Immunodeficiency Syndrome (AIDS) ou em português, a Síndrome da Imunodeficiência Adquirida (SIDA) tornou-se um dos maiores problemas de saúde pública e, segundo os dados epidemiológicos do Ministério da Saúde (MS), a epidemia vem aumentando a cada ano e estima-se que foram notificados, entre 2007 a 2016, no país, 842.710 casos de AIDS. Anualmente, tem-se registrado uma média de 41,1 mil casos de AIDS nos últimos cinco anos ${ }^{1}$.

A AIDS foi reconhecida em Los Angeles, em 1981, a partir da descrição de um tipo incomum de pneumonia, associada a condições de imunossupressão grave. Esse fato atraiu a atenção de cientistas, profissionais da saúde e da população em geral que desconheciam tal doença e muito menos o seu agente etiológico. Gerando pânico nas pessoas, inclusive nos profissionais que não sabiam como tratar os indivíduos que contraíam o Vírus da Imunodeficiência Humana (HIV), pelo medo da contaminação. Nesse mesmo período, as autoridades sanitárias supunham que as doenças infecciosas estavam controladas, em função das tecnologias e do saber médico da época, despertando comportamentos e respostas coletivos relacionados ao medo do contágio e de uma doença desconhecida².

Esta epidemia trouxe inúmeras repercussões na qualidade de vida de toda a população, no meio científico e na comunidade da saúde, alterando, acima de tudo, as relações interpessoais, seus comportamentos, seus valores e suas crenças no cotidiano ${ }^{3}$. Pode-se citar, por exemplo, a melhoria da qualidade do sangue no Brasil, o surgimento de organizações civis que atendam às necessidades de grupos sociais excluídos e a adoção de recursos materiais descartáveis nas instituições de saúde. Ao mesmo tempo, trouxe um padrão moral que estimulou um processo demarcatório de atitudes certas e erradas, de acordo com os padrões morais hegemônicos na sociedade ${ }^{3}$.

A partir das considerações até aqui expostas, o objeto deste estudo se delimitou na representação social do cuidado em saúde ao paciente com HIV/AIDS para a equipe de saúde e a questão que o norteou foi: qual a representação do cuidado em saúde ao paciente com HIV/AIDS para os profissionais de saúde? Desse modo, seu objetivo foi analisar o cuidado em saúde ao paciente soropositivo através da abordagem processual a partir das representações construídas pela equipe de saúde.

Conhecer as representações sociais do cuidado em saúde aos pacientes soropositivos para a equipe de saúde apresenta-se como imperativo, no sentido de contribuir tanto para a compreensão das relações e do processo de trabalho, como também para possibilitar a análise da humanização dos atendimentos e das próprias condições onde o trabalho se inscreve. Destaca-se, ainda, que pode contribuir para as relações humanas como um todo, inserindo-se na luta contra os preconceitos e as condutas desfavoráveis ao processo de humanização a esses pacientes. Por isso, se faz necessário reconhecer, no que diz respeito aos sujeitos que compõem essa equipe, as particularidades da problemática que os cercam bem como suas implicações na prestação do cuidado.

\section{MÉTODO}

Como caminho teórico-metodológico deste trabalho, adotou-se a Teoria das Representações Sociais, em sua abordagem processual, desenvolvida na perspectiva da Psicologia Social ${ }^{4}$. A abordagem processual foi escolhida para guiar a pesquisa por seu direcionamento aos aspectos constituintes das representações, traço característico que auxilia na compreensão do objeto de estudo delineado em seus múltiplos fatores intervenientes, e em virtude da complexidade apresentada pelo objeto de representação. Ela considera que o acesso ao conhecimento das representações sociais parte do entendimento do ser humano como produtor de sentidos, focalizando-se na análise das produções simbólicas, dos significados e da linguagem, através dos quais o sujeito constrói o mundo em que vive ${ }^{5}$.

Os participantes deste estudo foram 23 profissionais de saúde que realizam suas atividades laborais em dois hospitais universitários federais e suas ações estão voltadas para o Programa Nacional DST/AIDS. Este número foi alcançado a partir das recomendações metodológicas de Oliveira, Marques, Gomes e Teixeira ${ }^{6}$ que consideram que, nos estudos de representação social, este quantitativo pode ser utilizado se as entrevistas forem realizadas em profundidade, como é o caso do presente estudo. Foram entrevistados somente os profissionais com mais de seis meses de atividade profissional no contexto do cenário escolhido, todos os outros foram excluídos devido ao entendimento que o fator tempo configura-se como um determinante na elaboração das representações sociais.

Para a coleta de dados utilizamos o questionário sociodemográfico de caracterização dos sujeitos e a entrevista semi-estruturada individual em profundidade orientada por um roteiro temático. A abordagem do participante se deu em local reservado dentro do próprio serviço e as entrevistas gravadas. A discursividade dos sujeitos foi devidamente transcrita e analisada sob os postulados teóricos e metodológicos das Representações Sociais. A técnica de análise escolhida foi a técnica de análise de conteúdo lexical informatizada através da análise hierárquica descendente por meio do software Alceste $4.10^{7}$. Este software realiza a identificação dos conteúdos presentes em um conjunto de textos a partir de técnicas de estatística textual e análise lexical e tem a finalidade de realizar, automaticamente, a análise lexical de conteúdo por meio de técnicas quantitativas de tratamento de dados textuais, sem necessitar de leitura humana prévia. Sua aplicabilidade tem permitido o desenvolvimento de diversas pesquisas no Brasil e na Europa ${ }^{6}$. 
Buscou-se respeitar os procedimentos ético-legais que se constituíram no cumprimento e na utilização dos valores éticos previstos na Declaração de Helsinki e estabelecidos pelas Resoluções 196/96 e 466/12 do Conselho Nacional de Saúde, pelo Ministério da Saúde. 0 projeto deste estudo foi apreciado à análise e aprovado pelos Comitês de Ética em Pesquisa do Hospital Universitário Gaffrée e Guinle CEP-HUGG no 10/2011 e do Hospital Escola são Francisco de Assis - CEP-HESFA

\section{RESULTADOS}

Ao término da construção do corpus para a análise Alceste com as 23 entrevistas realizadas (23 U.C.I.), obtevese 439.356 caracteres. De acordo com o resultado da análise, o corpus é composto por 6.623 formas reduzidas diferentes, com o total de 84.759 ocorrências. 0 corpus foi dividido pelo software em 2.275 U.C.E. e, destas, 1.410 U.C.E foram selecionadas para a análise, representando $62 \%$ de aproveitamento do material exposto para análise. O tamanho da U.C.E. foi determinado pelo número de formas reduzidas contidas em cada uma. Utilizando como universo de análise as 1.410 U.C.E. selecionadas, o software gerou seis classes, quais sejam, Classe 1: A constituição da equipe de saúde e o processo de cuidar: definições, práticas e dificuldades; Classe 2: As formas de enfrentamento diante do diagnóstico positivo ao HIV; Classe 3: As memórias sociais sobre a AIDS: origem, circulação, informação e imagens; Classe 4: Atitudes profissionais: avaliações e julgamentos; Classe 5: A epidemia de AIDS nos dias atuais; Classe 6: As práticas de proteção adotadas pelos profissionais frente ao HIV.

Neste estudo será aprofundada a Classe 2, onde foi constatado o predomínio textual, que comportou 407 U.C.E, equivalendo $30 \%$ do corpus analisado, configurandose a maior de todas as classes denominada de "As formas de enfrentamento diante do diagnóstico positivo ao HIV". Esta classe refere-se aos aspectos positivos e negativos diante do diagnóstico positivo ao HIV: as redes de apoio familiar e profissional; o preconceito e a falta de apoio vivenciado, e as orientações e a educação em saúde. Frente a complexidade dos resultados, será realizada sua discussão em três subclasses, para que os contextos semânticos apresentados permitam uma compreensão do conteúdo geral expresso pela classe, abrangendo assim temáticas ligadas às formas de enfrentamento diante do diagnóstico positivo ao HIV.

\section{Subclasse 1: As principais redes de apoio social diante do diagnóstico positivo ao HIV: a construção representacional do acolhimento como importante ao cuidado em saúde}

Nesta primeira subclasse as principais redes de apoio social que são identificados pelos profissionais procedem da família e dos próprios profissionais de saúde diante do diagnóstico positivo ao HIV. O apoio social é definido como $\sim[\ldots]$ conjuntos hierarquizados de pessoas que mantêm entre si laços típicos das relações de dar e receber, e existem ao longo do ciclo vital, atendendo à motivação básica do ser humano à vida gregária; no entanto, sua estrutura e funções sofrem alterações, dependendo das necessidades das pessoas ${ }^{8}$.

Hierarquicamente definido como primeiro tipo de apoio identificado está o familiar. Ele é considerado uma estratégia de enfrentamento frente às dificuldades encontradas pelos pacientes portadores de diversos problemas de saúde, mais ainda, no que diz respeito ao HIV/AIDS. Neste último, a proximidade da família tende a aumentar a segurança e a auto-estima do paciente, encorajando-o a prosseguir no tratamento.

Isto porque é pela e na família que há produção de cuidados essenciais no contexto da Saúde, que vão desde "[...] interações afetivas necessárias ao pleno desenvolvimento da saúde mental e da personalidade madura de seus membros, passam pela aprendizagem da higiene e da cultura alimentar e atingem o nível da adesão aos tratamentos prescritos pelos serviços (medicação, dietas e atividades preventivas). Essa complementaridade se dá através de ações concretas no cotidiano das famílias, o que permite o reconhecimento das doenças, busca 'em tempo' de atendimento médico, incentivo para o autocuidado e, não menos importante, o apoio emocional"9.

Eles passam por isso, por essas fases, mas com apoio familiar essa pessoa reagirá bem diferente. Cada vez mais as pessoas estão sendo apoiados por seus familiares, seus pares e amigos. E36

Em vários estudos podemos encontrar afirmativas que o suporte social contribui positivamente para o enfrentamento do HIV $8,10-14$. Muitos destacam que esses indivíduos se sentem satisfeitos com relação a esse apoio, conferindo-lhe mais coragem para viver e conviver com a doença ${ }^{11-12}$. Salienta-se que a rede de apoio se faz necessária para substituir o sentimento de solidão que muitas vezes abate o indivíduo quando se descobre adoecido e também, das formas de sofrimento causadas pelo preconceito e abandono ${ }^{12}$.

No entanto, há relatos que o diagnóstico é ocultado por medo das repercussões negativas que podem ocorrer, tanto em relação à família como em relação ao paciente ${ }^{12-13}$. A negação é apontada como mecanismo de reação a ameaças reais e imaginárias decorrentes do temor do julgamento social e o medo da discriminação, mantendo a doença em segredo para se proteger. Frente a essas limitações e/ou dificuldades no cuidado e na convivência com quem adoeceu, é necessário criar estratégias de enfrentamento e adaptação. Essas devem ser discutidas com os profissionais de saúde que devem primar pelo cuidado tanto da pessoa que vive com o HIV como de sua família, tornando este momento menos estressante possível por meio da escuta, deixando-os 
exporem seus sentimentos e angústias oferecendo-lhes apoio necessário ${ }^{13}$.

Nesses casos, o relacionamento interpessoal estabelecido pela equipe de saúde é reconhecido como fundamental para o bom prognóstico da doença e também como co-participante das práticas de cuidado.

Entregar o resultado para uma pessoa pode ser HIV positivo ou HIV negativo, muitas vezes, a gente se surpreende pela pessoa ou pela historia. A gente se acostumou a se colocar nessa posição de quem entrega o resultado e tentar ser humano, tentando ser o mais neutra possível, para poder oferecer ajuda ao HIV positivo, mas sem absorver, o sofrimento e a dor do outro. E16

Principalmente diante do resultado de HIV positivo, a pessoa não vai querer te ouvir, é perda de tempo. Às vezes, você joga muitas palavras em vão. Você tem que respeitar o tempo do outro e, como aqui a gente não tem retorno, não adianta querer falar tudo. Eu digo sempre que o espaço está aberto para o que a pessoa precisar. E24

Ao receber o resultado do exame, esta relação evidenciase e são determinantes nas repercussões pessoais diante do resultado positivo. As representações que cada sujeito tem sobre si mesmo, assim como do diagnóstico positivo para o HIV são produzidas na cultura ao qual pertencem, diferenciando-se conforme as possibilidades de cada sujeito. Para os entrevistados, o diagnóstico positivo ao ser revelado, apresenta uma verdade ainda não concebida. A relação diante do resultado oferece ao sujeito uma interpretação de si mesmo que está relacionada com as representações do HIV/AIDS marcadas em nossa cultura, que está carregada por sentimentos negativos oriundos do início da epidemia, atribuindo a doença seu caráter letal, incurável e imersa em preconceitos.

A gente começa a pautar mais isso, respeitar o outro e começar a ver até que ponto o outro está podendo ouvir e até onde eu tenho direito de falar. E11

O receio e as dúvidas diante da nova realidade que a pessoa soropositiva ao HIV se depara, faz com que sejam aflorados sentimentos de insegurança e temor, mas que posteriormente podem ser dissipados ao sentirem-se acolhidos pelos profissionais e receberem as informações e os esclarecimentos com relação ao tratamento.

Eu fico me perguntando do meu papel diante da história dessa pessoa que vai carregar a minha figura para o resto da vida, pois eles dizem que se lembrará de quem Ihes entregou o resultado para sempre. E13

O impacto provocado pela comunicação diagnóstica é minimizado de acordo como é dada a notícia. A revelação da soropositividade agride o paciente e pode provocar danos, além de aumentar o sofrimento de quem recebe este diagnóstico. Uma forma de amenizar o sofrimento é o desenvolvimento da empatia, ou seja, colocar-se no lugar do outro.

A empatia é compreendida como uma habilidade de interação social e se constitui em um fenômeno multidimensional que engloba componentes cognitivos, afetivos e comportamentais. O cognitivo caracteriza-se pela adoção de perspectiva, que é compreendida como a capacidade de inferir acuradamente os sentimentos e pensamentos de alguém. O componente afetivo da empatia caracteriza-se por uma tendência a experimentar sinais de simpatia e de compaixão pelos outros, além de preocupação genuína com o bem estar da pessoaalvo. Essa tendência é conhecida como comportamento pró-social. O componente comportamental da empatia caracteriza-se por transmitir de forma verbal e não verbal, um reconhecimento explícito dos sentimentos e da perspectiva da outra pessoa, de tal maneira que ela se sinta realmente compreendida ${ }^{14}$.

É que a pessoa com AIDS é um ser humano como outro qualquer que necessita de afeto e carinho, e que podemos ter um relacionamento pessoal com ele não sendo necessário afastá-lo da sociedade. E17

A aceitação do profissional diante do diagnóstico positivo ao HIV sem acusações ou tentativas de culpabilização é fundamental para essa relação de ajuda. A postura ativa da equipe de saúde tende a facilitar o processo de adesão ao tratamento e a verificação de alguma dificuldade enfrentada por este paciente, bem como lançar mão de estratégias de apoio, tais como: diminuição do intervalo entre consultas e mudança no esquema terapêutico, quando possível.

Eu me sinto mais capacitada atualmente que no início, porque aprendi que não tenho que dar conta do sofrimento e tudo que passa na cabeça do sujeito. E14

Fico pensando que sou psicólogo e me formei para escutar. As pessoa com AIDS são todos sujeitos em sofrimento e essa é a primeira razão que me faz poder trabalhar. E11

O acolhimento e o cuidado empático minimizam os efeitos deletérios do diagnóstico positivo ao HIV e atenua sofrimento durante a continuidade do acompanhamento deste. $\mathrm{O}$ ato de cuidar e de compreender o processo saúde-doença enfoca valores tais como a fé, a esperança, a confiança, as necessidades humanas, a ética e a moral. Preconiza que o cuidador cultive sua sensibilidade e, ao desenvolver seus próprios sentimentos, ele será capaz de interagir com o outro. A empatia possibilita aceitar os sentimentos do outro sem reagir com raiva ou medo. Neste sentido, esta forma de cuidar é norteada pela capacidade de poder perceber o outro tal qual como ele é, constituindo a cerne do conceito de empatia. 


\section{Subclasse 2: As construções representacionais da AIDS e da pessoa com AIDS: o enfrentamento do preconceito e da falta de apoio}

Esta subclasse traz à tona a questão do preconceito e a falta de apoio vivenciado pela pessoa soropositiva ao HIV. Conforme explicitado anteriormente, o apoio familiar e dos profissionais de saúde são fundamentais como estratégias de enfrentamento diante das dificuldades encontradas e atuam como co-participante das práticas de cuidado. Além disso, promove o aumento da segurança e da auto-estima, bem como ameniza sentimentos de tristeza, revolta e depressão. No entanto, não podemos afirmar que todos os pacientes que vivenciam a experiência de conviver com o HIV podem contar com uma rede de apoio assim constituída.

Lá fora, se essa pessoa falar que é HIV positivo no trabalho, quem vai ficar com ele? Alguém vai parar para conversar? Se ele sentar na cadeira, alguém vai sentar onde ele estava sentado?E28

Do meu ponto de vista, são pessoas que precisam de ajuda, mas a sociedade por ser preconceituosa, não quer assunto. Acha que se beijar no rosto ou se apertar a mão vai pegar AIDS e que não quer nem ouvir falar. Tem gente que bota parente para fora de casa quando descobre. E27

O preconceito aparece das formas mais diversificadas possíveis. Os sujeitos mencionam atitudes discriminatórias direcionadas aos pacientes soropositivos tais como não compartilhar o mesmo assento, não querer conversar, beijar ou mesmo apertar a mão. Muitas vezes, nem familiares e amigos, os entes mais chegados, não se sentem aptos para esse convívio, ou mesmo, a própria pessoa soropositiva ao HIV se nega a informar sua condição por receio do preconceito familiar.

Observa-se que a convivência com o HIV implica ao indivíduo a vivência de sentimentos adversos, refletindo na impossibilidade de esquecimento da soropositividade, a medida em que a doença traz em si uma relevante carga de estigmatização, identificada na falta de oportunidade de trabalho, arrependimento, afastamento de amigos, discriminação familiar, acometimento de doenças que acarretam limitantes sequelas físicas, além do sentimento de fragilidade e impotência ante o preconceito ${ }^{15}$.

As dificuldades em lidar com situações de preconceito por parte dos pacientes foram mencionadas e justificam o medo e o receio que eles demonstram em contar para o outro sua situação sorológica e não ser aceito, o que the acarretaria uma série de transtornos psicológicos. 0 estigma e o preconceito para com as pessoas que vivem com HIV/AIDS determinam várias de suas atitudes, muitas vezes levando-as a mentir para não expor sua sorologia ${ }^{16}$.

O abandono acontece quando a família não quer levar a pessoa com AIDS para casa, tem o histórico de afastamento familiar, às vezes é um andarilho que nunca se adequou as convenções da sociedade e, é muito difícil para essa família cuidar dessa pessoa com AIDS. E12

As repercussões na vida do sujeito após a descoberta da soropositividade, comumente se dá no convívio social (amigos, família e serviços de saúde). Inclusive, algumas pesquisas ${ }^{12-13,16}$ demonstram que a discriminação começa a partir da própria família e se estende pela sociedade em geral. Por esse motivo, o medo do preconceito, da solidão e do abandono acompanha esses pacientes após o resultado positivo pra o vírus da HIV, interferindo inclusive no seu tratamento ${ }^{16}$.

Não tenho nenhum amigo ou parente que tenha me dito que tem HIV. As pessoas ainda têm essa coisa de se proteger, de não revelar, não falar sobre isso. E12

Eu tento junto com a pessoa com AIDS ver alguma forma dele se sentir abraçado sem se sentir renegado. Ele não pode sentir o preconceito na pele, pois é uma condição nova e pode vir a depressão e outros fatores junto disso. E11

Em relação à descoberta da soropositividade e transformações ocasionadas por ela, o indivíduo e a família, ao ter conhecimento da doença, experimentam uma diversidade de sentimentos e comportamentos ditos negativos. No entanto, à medida que são esclarecidos sobre a doença e informados sobre as possibilidades de tratamento e prognóstico, tais sentimentos foram se transformam.

Em uma pesquisa com adolescentes, é relatada que a revelação sobre o diagnóstico é feito apenas para algumas pessoas devido o preconceito. Eles não compartilhavam o problema com amigos, familiar ou namorado por medo da reação de ignorância e afastamento. Relatam inclusive que vivenciaram preconceito por parte dos profissionais de saúde demonstrado por expressões faciais e evitando o toque ${ }^{17}$.

Nas décadas de 80 a 90, o perfil representacional da AIDS, caracterizado pela morte e pelo medo, ficou associado a práticas profissionais de cuidado caracterizadas pelo distanciamento físico e uso de técnicas de autoproteção profissional exacerbadas. 0 distanciamento psicossocial também foi observado durante 0 desenvolvimento das práticas de cuidado. As representações foram se constituindo e moldando as características concretas da doença e às práticas de autoproteção impostas pela insuficiência de conhecimentos científicos, pela alta mortalidade observada e pelo medo da contaminação ${ }^{18}$.

Porém, os dados encontrados nesta pesquisa, nos mostram que, segundo os profissionais, eles não possuem preconceitos e demonstram com isso que, não há interferência da discriminação em seu relacionamento com o paciente soropositivo ao HIV.

A minha vivência com a AIDS na minha vida pessoal repercute bem, pois não tenho preconceito e passo isso 
para as pessoas da sociedade na qual eu vivo e, eles percebem que eu não tenho preconceito. E 25

Nós não temos preconceito com nada, mas o atendimento será direcionado. Na minha vida pessoal, não conheço nenhuma pessoa declaradamente HIV positivo e nunca ninguém se declarou para mim, apesar de saber que trabalho com isso. E14

Acho que nos podemos lidar e olhar para a pessoa com AIDS de frente, sem preconceito. E11

Segundo Oliveira ${ }^{19}$, na segunda metade dos anos 2000 e início de 2010 observa-se mudança no processo de determinação das relações entre pensamento e ação. As praticas de saúde assumem outra dimensão do que aquela observada no início da epidemia, talvez assim configurada a partir da compreensão dos processos e mecanismos de infecção do HIV. Atrelado a isso, está a forte influência do tratamento farmacológico e das diretrizes do Programa Nacional de HIV/AIDS do Brasil. Em função disso, podemos observar um processo de naturalização da síndrome, inserindo-a no que tange o conjunto de doenças crônicas.

O preconceito ainda existe e as pessoas carregam isso com elas. É um tanto complicado, mas não para mim, que os trato normalmente. Eu abraço e beijo, porque nós sabemos que o modo de transmissão não é pelo contato. E11

Então, não muda nada, a vida é a mesma. Eu tenho amigos HIV positivo e convivo normalmente sem problemas com eles. E 12

Apesar do preconceito ainda fazer parte da vida do paciente soropositivo, lidar com o HIV, para muitos profissionais, tanto no trabalho quanto em sua vida pessoal privada é algo relatado como normal e cotidiano. Os conhecimentos adquiridos pelos profissionais de saúde ao longo do período em que trabalham na assistência destes pacientes foram determinantes para a mudança desse paradigma. A experiência do convívio com a doença gerou a normalidade atribuída ao cuidado. Sendo assim, o estresse relatado no início da epidemia se desfaz devido à segurança e o preparo profissional agora sedimentado pela informação.

\section{Subclasse 3: As informações e as orientações no processo de enfrentamento: os desafios dos profissionais em face do universo consensual}

A última subclasse trata das orientações e a educação em saúde do paciente como estratégias de enfrentamento. Verifica-se que os profissionais a objetivam como parte do processo de organização de suas vidas, favorecendo a permanente formação e transformação de pensamento, ajudando-o na (re)construção das percepções de si e dos outros. Sendo assim, o processo de reorganização da vida do paciente soropositivo ao HIV é visto pelos profissionais de saúde como essencial para a efetivação do cuidado humanizado.
A representação social de educação em saúde com pessoas vivendo com HIV/AIDS tem confluência com o cuidado, com elementos do processo pedagógico. Se levarmos em consideração a assertiva de que a humanização no cuidado se faz presente em ações resolutivas, avaliação clínica e reconhecimento do direito da pessoa à informação, há uma associação entre educação em saúde e cuidado humanizado. No entanto, alguns relatos demonstram que os profissionais encontram dificuldades nesse processo de orientação. Isto pode ocorrer devido à baixa escolaridade, falta de instrução dos pacientes e/ou seus familiares, ou mesmo devido à imagem social da morte ainda vinculada à AIDS, tornando a aceitação mais difícil.

Constatou-se também que a falta de conhecimento sobre a doença é um fator predisponente ao preconceito, sendo determinante, muitas vezes, pela exclusão do indivíduo levando-o a marginalidade. A não aceitação por parte de seus pares faz com que haja negação da doença por medo de não ser aceito e perder o contato com os entes queridos.

Muito difícil de lidar, pois quando sabe, a maioria não aceita porque falta instrução. As pessoas ainda acham que ser HIV positivo leva a morte e a gente tenta explicar que não é assim. Existe tratamento. E13

Com o advento da descoberta dos antirretrovirais e a possibilidade do controle da doença e seus agravos, o sentimento de morte iminente foi dando lugar ao sentimento de esperança no futuro. A possibilidade de viver gerou a expectativa de conquistar novos horizontes e a capacidade desses pacientes reorganizarem suas vidas. Mas ainda assim, os familiares e as pessoas que convivem com a pessoa soropositiva ao HIV também sentem essa dificuldade e necessitam ser orientados.

Atualmente as pessoas conseguem conviver com alguém que é HIV positivo sem o medo de apertar a mão, de abraçar, de beijar que vai pegar. Pode ser que em alguns casos ainda tenha, mas diminuiu bastante. E 12

Ali aprendi que tudo que a pessoa fala quando senta comigo, eu não sou obrigada a saber naquele momento, mas preciso buscar. Tenho que saber a religião, o ambiente que ela vive e com quem ela se relaciona e onde mora. Não tenho que saber de fato tudo sobre o que ela fala, mas ter pelo menos uma noção, para a pessoa não pensar que eu não sei de nada. E14

Além disso, alguns profissionais ainda se sentem incapacitados em orientar os pacientes. Os fatores limitantes ao agir educativo em contextos HIV/AIDS são internospessoais (baixa valorização da ação educativa pelos profissionais), e externos-estruturais, que se manifestam na perspectiva sócio-política (baixa capacitação e formação para educação em saúde), infraestruturais (falta espaço adequado para as ações educativas), e infra-gerenciais (falta avaliação qualitativa) ${ }^{20}$. 
O trabalho em saúde se dá com base em encontros: entre profissionais e entre eles e os usuários. Isso no âmbito da educação em saúde pressupõe que esta deve ser vista de forma permanente e integrada. Reforçando a idéia que os profissionais que atuam no campo da saúde desempenham um duplo papel de educador: junto à população usuária das unidades e com as equipes de saúde, e em ambos os processos educativos são mediadores e facilitadores de aprendizagens, o que conforma tanto os processos de educação em saúde como de educação no trabalho ${ }^{19}$.

As representações sociais construídas pelos profissionais sobre educação em saúde com pessoas vivendo com para HIV, reforçam a evolução do respeito e do aprendizado com o passar do tempo. A orientação-prevenção permitem entender e mesmo explicar uma realidade que é específica dos tempos de AIDS, buscando compreender e facilitar a aceitação do tratamento do usuário. Esse dado revela que a experiência no desenvolvimento da prática de cuidado influencia e determina sobremaneira a construção dessas representações acerca destes indivíduos.

\section{CONCLUSÃO}

A partir desta análise, foi possível compreender como a rede social pode contribuir positivamente quanto negativamente em diferentes formas para a obtenção da qualidade de vida da pessoa que vive com HIV/AIDS. Sua reação diante do diagnóstico positivo pode variar de acordo com a representação de preconceitos sociais que foram construídos ao longo da vida, dentro da própria família e na roda dos amigos, nos relacionamentos.

Verificou-se que a descoberta do diagnóstico de soropositividade gera grande impacto na vida dos pacientes e seus familiares e que as mudanças advindas a partir dessa notícia possibilitam o surgimento de sentimentos distintos, que afloram em diferentes intensidades e manifestações, gerando traumas, dores, medos, preconceitos e discriminações. Tal situação abre um leque de possibilidades para a atuação profissional da área da saúde no sentido de apoiar, incentivar, informar e colaborar com esse paciente e sua família.

Sendo assim, é necessário trabalhar as questões relativas ao HIV/AIDS - dúvidas e preconceitos - e esclarecendo seu importante papel de apoio, tanto no período de descoberta de sua sorologia, quanto ao longo de sua vida. Afinal, muitas vezes, o preconceito está relacionado à escassez de informações claras e corretas a respeito da doença, levando com que esses pacientes sejam abandonados.

A implantação de políticas públicas e a reorientação dos serviços de saúde para o atendimento especializado constituiu-se como formas de enfrentamento da síndrome, pois determinaram novas práticas profissionais direcionadas ao enfrentamento dos aspectos negativos da doença. Pode-se destacar que o a partir da informação, houve a maior aproximação no relacionamento interpessoal na realização das práticas de cuidado e o uso seletivo de técnicas de autoproteção profissional.

Além disso, o conhecimento dos profissionais revela conteúdos que são refletidos em suas ações práticas durante a realização do cuidado. As atitudes de respeito e não discriminação, muitas vezes, é consequência da busca por conhecimento e informação e demonstram, além de legitimar atitudes de enfrentamento da doença tais como o apoio ao tratamento, a solidariedade por parte deste cuidador. Estas atitudes são demonstradas no relacionamento interpessoal estabelecido pela equipe de saúde ao paciente soropositivo ao HIV e, a partir delas é possível estabelecer uma rede de apoio, fundamental durante o diagnóstico de positividade, momento de fragilidade do paciente e no decorrer do enfrentamento da doença, com incentivo à adesão ao tratamento.

Considerando os achados deste estudo, relativos tanto ao âmbito pessoal quanto na vida desses profissionais de saúde, apesar de ter atingido os objetivos previamente delineados, possui percalços que impedem a generalização dos seus resultados. Sendo assim, urge a necessidade de tecer outras discussões sobre os resultados, propondo caminhos para outros estudos e pesquisas, seja com grupos profissionais específicos, instituições, setores e sociedades.

\section{REFERÊNCIAS}

1. Ministério da Saúde (BR). Boletim Epidemiológico AIDS: Versão Preliminar- Ano $\mathrm{V} \mathrm{n}^{\circ} 1-27^{\mathrm{a}}$ a $53^{\mathrm{a}}$ semanas epidemiológicas - julho a dezembro de 2015/01 a $26^{a}$ semanas epidemiológicas - janeiro a junho de 2016. Brasília (DF): MS [Internet]. 2016. [citado em 27 mai 2017]. Disponível em: <http://www.aids.gov.br/data>.

2. Villarinho MV, Padilha MI, Berardinelli LMM, Borenstein MS, Meirelles BHS, Andrade SR. Políticas públicas de saúde face à epidemia da AIDS e a assistência às pessoas com a doença. Rev Bras Enferm. [Internet]. 2013 [citado em 20 nov 2014]; 66:2717. Disponível em: <http://www.scielo.br/scielo.php?script=sci_ arttext\&pid=S0034-71672013000200018\&lng=en>.

3. Daniel H, Parker R. AIDS: A terceira epidemia. São Paulo (SP): Iglu; 2001.

4. Sá CP. Núcleo central das representações sociais. $2^{a}$ ed. Petrópolis (RJ): Vozes; 2002.

5. Banchs MA. Leitura epistemológica da Teoria das Representações Sociais. Em: Almeida AM, Santos MFS, Trindade ZA. Organizadores. Teoria das Representações Sociais: 50 anos. Brasília (DF): Technopolitik; 2011. p. 225-258.

6. Oliveira DC, Marques SC, Gomes AMT, Teixeira MCTV. Análise das evocações livres: uma técnica de análise estrutural das representações sociais. In: Paredes AS. Perspectivas teóricometodológicas em representações sociais. João Pessoa (PB): Editora Universitária UFPB; 2005 p.573-603.

7. Alceste. Version 4.10. Toulouse: IMAGE, c2010. Programa de computador.

8. Andrade HAS, Silva SK, Santos MIPO. AIDS em idosos: vivências dos doentes. Esc. Anna Nery. 2010 Out-Dez; 14(4):712-719. 
9. Gutierrez DMD, Minayo MCS. Produção de conhecimento sobre cuidados da saúde no âmbito da família. Cien Saude Colet. 2010; 15(Supl.): 1497-1508.

10. Suit D, Pereira ME. Vivência de estigma e enfrentamento em pessoas que convivem com o HIV. Psicol USP. 2008 Jul-Set; 19(3):317-40.

11. Orlandi FS, Praça NS. A esperança na vida de mulheres com HIV/AIDS: Avaliação pela escala de Herth. Texto Contexto Enferm. 2013 Jan-Mar; 22(1):141-8.

12. Galvão MTG, Paiva SS. Vivências para o enfrentamento do HIV entre mulheres infectadas pelo vírus. Rev. bras. enferm. 2011 Nov-Dez; 64(6):1022-1027.

13. Botti LM, Leite BG, Prado FM, Wadman PAM, Marcon, SS. Convivência e percepção do cuidado familiar ao portador de HIV/AIDS. Rev. enferm. UERJ. 2009 Jul-Set; 17(3):400-405.

14. Falcone E. Empatia. In: Abreu CN, Roso M, organizadores. Psicoterapias cognitiva e construtivista: novas fronteiras da prática clínica. Porto Alegre (RS): Artmed; 2011. p. 275-288.

15. Medeiros APDS, Araújo VS, Moraes MN, Almeida SA, Almeida JN, Dias MD. A experiência da soropositividade para grávidas com HIV/AIDS: preconceito, dor, trauma e sofrimento pela descoberta. Rev. enferm. UERJ. 2015 Mai-Jun; 23(3):362-67.

16. Cardoso AL, Marcon SS, Waidmani MAP. Impacto da descoberta da sorologia positiva do portador de HIV/AIDS e sua família. Rev. enferm. UERJ. 2008 Jul-Set; 16(3):326-332.

17. Fernandes ES, Almeida IS, Costa CCP, Ribeiro IB. A vivência do ser-adolescente com HIV/AIDS: um estudo fenomenológico para a enfermagem Rev. Enf. Profissional. 2014 Jul-Dez; 1(2):447-61.

18. Oliveira DC. Construção e transformação das representações sociais da aids e implicações para os cuidados de saúde. Rev. Latino-Am. Enfermagem [Internet]. 2013 [citado em 12 jul 2016]. 21(Spec): 276-86. Disponível em: <http://www.revistas.usp.br/rlae/ article/view/52952/56962>.

19. Araújo FP; Ferreira MA. Representações sociais sobre humanização do cuidado: implicações éticas e morais. Rev Bras Enferm. 2011 Mar-Abr; 64(2):287-93.

20. Marques SC, Tyrrell MAR, Oliveira DC. As práticas educativas na prevenção do HIV/AIDS das usuárias da rede básica de saúde do Rio de Janeiro/Brasil. REME Rev Min Enferm [Internet]. 2013 [citado em 4 jun 2016]. 17(3):538-53. Disponível em: <http://www.reme.org.br/artigo/detalhes/671>. 